\title{
Berichten allein reicht nicht
}

\section{Liebe Leserinnen und Leser,}

das Thema Nachhaltigkeit begleitet uns schon länger. Bereits vor 20 Jahren befassten sich Forscher mit Themen wie Umweltbilanz und Umwelt-Controlling. Und in der ersten WHU-Studie zur Zukunft des Controllings vor zehn Jahren war das Thema Nachhaltigkeit auf Anhieb auch in den Top Ten der befragten Finanzvorstände und Controller vertreten. Dennoch ist in der ganzen Zeit nicht viel Nachhaltiges passiert. Noch immer wird Green Finance in der Regel darauf reduziert, wie man den zunehmenden externen Berichtsanforderungen gerecht wird und gegenüber dem Kapitalmarkt und anderen Stakeholdern seine grüne Seite herausputzt. Noch immer gilt das Primat der kurzfristigen Effizienz- und Performance-Maximierung, nur die Rahmenbedingungen des wirtschaftlichen Handelns wurden um einen gewichtigen Themenblock erweitert. Noch immer ist es so, dass Unternehmen nur dann in Ökologie oder sozial motivierte Aktivitäten investieren können, wenn sich das auch kurz- bis mittelfristig rechnet oder eben Politik, Gesellschaft und Kapitalmarkt gewisse Mindeststandards einfordern. Entsprechend ist ein Mehr an Nachhaltigkeit nur dann erlaubt, wenn sich ein nachhaltig wirkendes Produkt profitabler verkaufen oder wenn sich eine Sparmaßnahme unter Verweis auf die Ökologie besser begründen lässt, wenn ein soziales oder ökologisches Image Zahlungsbereitschaft und Kundenbindung messbar steigert oder wenn sich die gesetzlichen Anforderungen erhöhen. Viel Arbeit, viel Potenzial, aber im Kern nichts grundlegend Neues. Entsprechend ist die Nachhaltigkeit in den Folgestudien der Jahre 2014, 2017 und 2020 auch wieder aus der Liste der wichtigsten Themen auf der Agenda des Controllings verschwunden.

Dennoch scheint sich langsam etwas zu verändern, der Status quo beim Thema Nachhaltigkeit und Finance unter Druck zu kommen: Nicht nur die Fridays-for-Future-Bewegung, die Forderungen des einen oder anderen Großinvestors und der Auftritt mancher Vorstandssprecher in Davos signalisieren, dass der aktuelle Umgang mit dem Thema der ökologischen Nachhaltigkeit die gesellschaftliche Betriebserlaubnis auf Dauer gefährden kann. Und die Spannungen in vielen Ländern der westlichen Hemisphäre legen zumindest den Gedanken nahe, dass auch das Thema der sozialen Nachhaltigkeit weit über ein Verbot von Kinderarbeit in Entwicklungsländern hinaus an Relevanz gewonnen

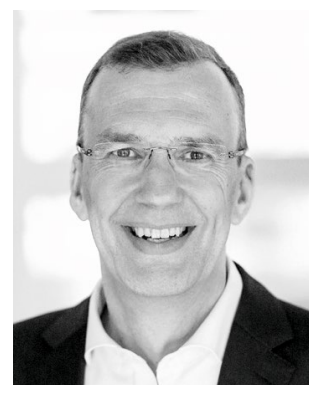

Utz Schäffer

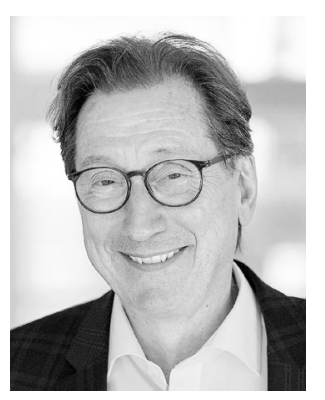

Jürgen Weber hat. Und schließlich wirft nicht zuletzt die aktuelle Covid19-Pandemie die Frage auf, ob und wie Unternehmen ihre ökonomische Nachhaltigkeit und ihre Resilienz in einem Kontext immer wiederkehrender externer Schocks erhöhen können. Vieles spricht also dafür, dass sich das notwendige Maß an ökologischer, sozialer und ökonomischer Nachhaltigkeit weiter erhöhen wird, betriebswirtschaftliches Denken langfristiger werden sollte und eine weitgehende Reduktion des Themas auf Marketing und Compliance immer weniger ausreicht. Wenn dem aber so ist, betrifft das auch die Finanzfunktion: Sie muss sicherstellen, dass auf die hehren Sprüche in Davos sowohl bei Investitionsentscheidungen als auch im Alltag der Unternehmenssteuerung Taten folgen. Berichten allein reicht nicht mehr aus.

Wir haben daher nicht nur den Schwerpunkt des aktuellen Heftes dem Thema Nachhaltigkeit gewidmet, sondern werden auch in diesem und den Folgeheften in den Dialog treten und mit Günther Bachmann, Thomas Kusterer und Melanie Keis über die verschiedenen Facetten von Nachhaltigkeit und Unternehmenssteuerung sprechen.

Viel Spaß bei der Lektüre wünschen Ihnen
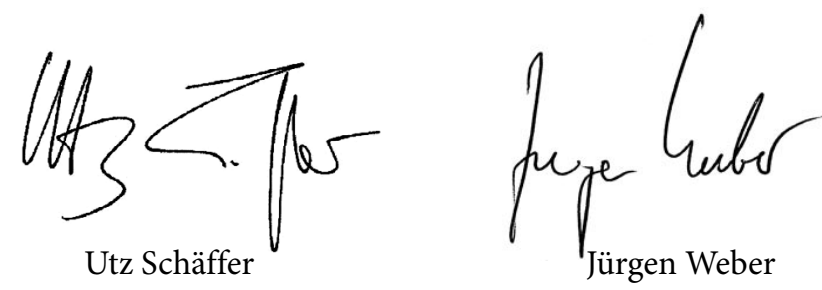